
\title{
25 Research Soure \\ Using modern day imaging to reveal secrets hidden within mummy cartonnage
}

Adam Gibson

Kathryn E. Piquette

Uwe Bergmann

William Christens-Barry

Graham Davis

Marco Endrizzi

Shuting Fan

Sina Farsiu

Anthony Fitzgerald

Jennifer Griffiths

Cerys Jones

Guorong Li

Phillip L. Manning

Charlotte Maughan Jones

Roberta Mazza

David Mills

Peter Modregger

Peter R. T. Munro

Alessandro Olivo

Alice Stevenson

Bindia Venugopal

Vincent Wallace

Roy A. Wogelius

Michael B. Toth

Melissa Terras

\section{Video Abstract}

Keywords: mummy cartonnage, papyrus, phantom, surrogate, heritage imaging, Heritage Science, ancient Egypt, mummies, Egyptian, multispectral imaging, transillumination, optical coherence tomography, X-ray fluorescence imaging, X-ray fluorescence spectroscopy, X-ray micro computed tomography, phase contrast $\mathrm{X}$-ray, terahertz imaging, optical imaging, carbon-based ink, iron-based ink

Posted Date: September 20th, 2019 
DOI: https://doi.org/10.21203/rs.2.15065/v1

License: (c) (1) This work is licensed under a Creative Commons Attribution 4.0 International License. Read Full License 


\section{Abstract}

Rich with clues into human history, Egyptian mummies have intrigued researchers for centuries. But it isn't just the preserved bodies that contain valuable information: many mummies were covered with an outer casing called cartonnage, which included layers of recycled papyrus containing text from ancient writings. Although a rich source of information, accessing the textual content of these recycled materials without destroying the attendant mummies has been challenging. Now, powered by a grant from the Arcadia Fund, an international team of investigators has compared the abilities of different modern-day imaging methods to reveal this text, which may offer a new, non-destructive way for researchers to peer into the past. The team selected eight imaging techniques expected to give contrast to hidden organic and inorganic pigments buried within layers of papyrus. For testing, they created four so-called phantoms. Each phantom comprised four sheets of modern papyrus, and each sheet was marked with a cross on one of four quadrants. This arrangement allowed the crosses to be placed underneath zero, one, two, or three sheets of papyrus when imaging. A different ink was used for each phantom - three inks represented those used historically, and one modern ink served as a reproducible control. The phantoms were visualized using multispectral imaging, transillumination, optical coherence tomography, X-ray micro computed tomography, X-ray fluorescence spectroscopy, X-ray phase contrast imaging, and terahertz imaging. Each method provides a unique image-generating mechanism, accompanied by distinct advantages and disadvantages. The results showed that no single imaging technique performed best in all cases. Multispectral imaging, for example, showed excellent surface detail of both iron- and carbon-based inks, but poor penetration. The X-ray techniques, on the other hand, clearly identified ironbased inks even under many layers of papyrus, but could not detect carbon-based inks. A full examination of a piece of cartonnage will therefore require a multimodal approach, with each technique providing complementary information. Although ancient cartonnage has a more complex geometry and composition than the test phantoms, these findings support that imaging can not only safely detect whether text is present within a mummy's outer casing, but in some circumstances, it may even allow the writing to be read. 